\title{
A VACINAÇÃO OBRIGATÓRIA COMO UM DEVER JURÍDICO DECORRENTE DO DIREITO FUNDAMENTAL À SAÚDE
}

\author{
MANDATORY VACCINATION AS A LEGAL DUTY DUE TO \\ FUNDAMENTAL RIGHT TO HEALTH
}

\author{
José Renato Venâncio Resende \\ Universidade Federal de Uberlândia (Uberlândia, MG, Brasil) \\ Cândice Lisbôa Alves \\ Universidade Federal de Uberlândia (Uberlândia, MG, Brasil)
}

Recebimento: 7 out. 2019

Aceitação: 15 abr. 2020

\begin{abstract}
Como citar este artigo / How to cite this article (informe a data atual de acesso / inform the current date of access):
RESENDE, José Renato Venâncio; ALVES, Cândice Lisbôa. A vacinação obrigatória como um dever jurídico decorrente do direito fundamental à saúde. Revista da Faculdade de Direito UFPR, Curitiba, v. 65, n. 2, p. 129-148, maio/ago. 2020. ISSN 2236-7284. Disponível em: https://revistas.ufpr.br/direito/article/view/69582. Acesso em: 31 ago. 2020. DOI: http://dx.doi.org/10.5380/rfdufpr.v65i2.69582.
\end{abstract}

\section{RESUMO}

No Brasil, desde 1975 é compulsória a vacinação relativa a certas doenças, de acordo com as normas do Ministério da Saúde, ressalvados tão somente os casos de expressa contraindicação médica. O tema, historicamente, já causou grande insatisfação popular e, atualmente, crescem os movimentos que resistem à obrigação de se vacinar, mesmo que a arrepio da lei. Desse modo, considera-se importante que tal questão seja analisada à luz dos direitos fundamentais, sobretudo do direito à saúde. Nesse sentido, o artigo se dispõe a investigar a vacinação obrigatória, buscando sua identificação como direito e/ou dever jurídico fundamental. A hipótese é de que o cumprimento de tal dever bem como a referida limitação são necessários para que o direito à saúde (pública) seja efetivado. O objetivo da pesquisa, por sua vez, é melhor compreender a intersecção entre direitos e deveres fundamentais e, no caso da saúde pública, como estes impõem à população a imunização obrigatória. A pesquisa é teórica, aplicando-se o método hipotético-dedutivo de abordagem e o bibliográfico quanto ao procedimento. Ao final confirmou-se a hipótese do trabalho, levantada no sentido de ser obrigatória a vacinação como pressuposto de efetivação do direito à saúde de todos.

\section{PALAVRAS-CHAVE}

Vacinação obrigatória. Deveres fundamentais. Direitos fundamentais. Direito fundamental à saúde.

\begin{abstract}
In Brazil, vaccination against certain diseases has been compulsory since 1975, in accordance with the rules of the Ministry of Health, except only for cases of express medical contraindication. Historically, the issue has already caused great popular dissatisfaction and, today, there are growing movements that resist the obligation to be vaccinated, even if against the law. Thus, it is considered important that this issue is analyzed in the light of fundamental rights, especially the right to health. In this sense, the article is willing to investigate mandatory vaccination, seeking its identification as a fundamental right and/or legal duty. The hypothesis is that the fulfillment of such a duty as well as
\end{abstract}


the aforementioned limitation are necessary for the right to (public) health to be realized. The objective of the research, in turn, is to better understand the intersection between fundamental rights and duties and, in the case of public health, how these impose mandatory immunization on the population. The research is theoretical, applying the hypothetico-deductive approach and, to the procedure, the bibliographic method. In the end, the work hypothesis was confirmed, raised in the sense that vaccination is mandatory as a prerequisite for the realization of everyone's right to health.

\section{KEYWORDS}

Mandatory Vaccination. Fundamental duties. Fundamental rights. Fundamental right to health.

\section{INTRODUÇÃO}

No dia 5 de setembro de 2013, em Jacareí, interior do estado de São Paulo, a Promotoria da Infância e da Juventude ajuizou ação civil pública contra os pais de duas crianças que se recusavam a vaciná-las sob a alegação de que o tratamento homeopático dispensado aos filhos era suficiente para mantê-los imunizados e protegidos contra doenças contagiosas e que a vacinação colocaria em risco a vida dos menores. A promotoria, por sua vez, fundamentou seu pedido no direito individual de proteção integral da saúde da criança e também na repercussão da não vacinação na rede de saúde pública, ambos os argumentos acolhidos pelo juízo, que, em decisão liminar proferida no dia 24 de setembro, determinou que os pais teriam cinco dias para providenciar a vacinação das duas crianças, sob pena de multa diária de um salário mínimo. Foi determinada, ainda, a expedição de mandado de busca e apreensão dos infantes, que seriam encaminhados à Secretária de Saúde do município para que recebessem as vacinas, caso os pais persistissem no descumprimento da decisão pelo período de dez dias (SÃO PAULO, 2013).

Ainda que, segundo a promotora responsável pela ação, trate-se de um caso sem precedentes no Brasil, o movimento antivacina pode ser considerado tão antigo quanto a própria prática da vacinação e tem se expandido por diversos motivos, de forma significativa, nos últimos anos, a ponto de causar baixas nas taxas brasileiras de vacinação. Por exemplo, em 2017, dos 5.570 municípios brasileiros, 1.453 não atingiram as metas de cobertura mínima de vacinação, o que gera o risco de retorno de algumas doenças até então sob controle, devido ao aumento exponencial de pessoas não imunizadas (CANCIAN, 2018).

Tal situação tem se mostrado preocupante e relevante, pelo que merece a atenção do Direito, uma vez que a vacinação obrigatória interfere na liberdade e na saúde individual do sujeito, enquanto a recusa à vacinação pelo indivíduo ou por seus responsáveis pode colocar em risco a saúde da coletividade, ou seja, pode-se pensar a questão pela perspectiva de um conflito entre direitos individuais e coletivos, ambos, todavia, fundamentais e de natureza muito próxima, o que dificulta, 
já de início, um consenso sobre eles. Todavia, apesar da (presumida) importância desse tema, constata-se uma ausência de proposições legais ou doutrinárias que deem uma resposta efetiva à recusa de se vacinar. Em síntese, embora haja algumas normas que determinam a vacinação obrigatória de toda a população, não há nenhuma sanção penal para quem se nega a fazê-lo, restando a coação na órbita cível, como no caso trazido a lume, com a hipótese de condução coercitiva. Por outro lado, devido ao crescimento da resistência à vacinação, começam a surgir ações judiciais, como a proposta pelo parquet em Jacareí, ademais de preocupações de especialistas referentes às possíveis consequências da baixa imunização populacional (LEVI, 2013).

Então, a partir da regulamentação estatal a todos dirigida no sentido de tornar obrigatória a vacinação, o que interfere no campo de escolhas do indivíduo sobre como cuidar da própria saúde ou da de seus filhos, surge o problema aqui tratado, qual seja, a natureza jurídica da vacinação obrigatória: se direito ou dever, e a quem caberia esse dever, caso se configurasse como tal.

A princípio, considera-se que a vacinação obrigatória é um dever fundamental dirigido a todos e equivalente ao direito fundamental à saúde. Ao mesmo tempo, não se pode negar que o direito fundamental à saúde é dotado de uma dimensão positiva (prestacional) e outra negativa (defensiva, de não intervenção), sendo que esta exige do Estado o respeito e a não ingerência na saúde do indivíduo. Enquanto a vacinação obrigatória visa cumprir a dimensão positiva de todos, ao promover a saúde pública, ela também limita a dimensão negativa do direito fundamental à saúde. Eis o fundamento do problema: a colisão entre os aspectos positivos e negativos de um mesmo direito.

A hipótese levantada é de que, embora não seja uma situação ideal, visando à proteção da coletividade, a limitação imposta à dimensão negativa do direito fundamental à saúde por meio do dever fundamental da vacinação é uma conditio sine qua non para a existência desse direito, reforçando o caráter de dever estatal e não mero direito da pessoa quanto à vacinação obrigatória. Isto é, se o Estado não garantir a incolumidade da saúde pública por meio da imunização da população (um meio cuja eficácia tem sido cientificamente comprovada há séculos), o próprio direito à saúde correria o risco de sucumbir diante das epidemias que poderiam vir a se instalar novamente e que seriam, por seu turno, preocupações do próprio Estado.

O método de pesquisa utilizado foi o hipotético-dedutivo quanto à abordagem e o bibliográfico quanto ao procedimento. Utilizaram-se como fontes primárias doutrinas acerca do direito à saúde e vacinação, além de consulta à legislação e a fatos noticiados em jornais e em textos médicos sobre vacinas, bem como a artigos de História e de História do Direito. O objetivo foi melhor compreender o desenvolvimento de normas e políticas públicas de imunização, além de analisar a 
relação entre direitos e deveres fundamentais, para, de tal intersecção, apontar como o sistema jusfundamental autorizaria a imposição imunizante.

A estrutura deste trabalho, por sua vez, dividiu-se em quatro itens, de acordo com o que se considerou necessário discutir: o primeiro, acerca do histórico da criação das vacinas e da obrigação de se vacinar; o segundo, sobre os movimentos contrários à vacinação e suas justificativas; o terceiro, quanto ao dever fundamental de imunização e o direito fundamental à saúde, considerado em sua dupla dimensionalidade; e, por último, apresentam-se as considerações finais.

\section{BREVE HISTÓRICO DAS POLÍTICAS PÚBLICAS DE VACINAÇÃO OBRIGATÓRIA}

As vacinas podem ser definidas como intervenções, de caráter preventivo, reconhecidas pela eficácia na diminuição da mortalidade causadas por doenças imunopreveníveis (BARBIERI; COUTO; AITH, 2017), ou seja, justamente aquelas moléstias que podem ser prevenidas por meio da vacinação. Em suma, sua função no organismo humano é estimular o sistema imunológico na produção de anticorpos, a partir de uma amostra enfraquecida ou inativa do agente causador da doença a ser evitada (BALLALAI, 2016, p. 11-12). No Brasil, a vacinação em massa, tal qual ocorre na grande maioria dos países, baseia-se na “imunização de rebanho”, pela qual os indivíduos vacinados protegem a si e aos não vacinados, o que pode levar ao controle e, até mesmo, à eliminação da circulação do agente infeccioso (BARBIERI; COUTO; AITH, 2017, p. e00173315). Sua importância é tamanha, que o Center for Disease Control and Prevention (CDC), dos Estados Unidos, considerou a imunização como a maior conquista sanitária do século XX (LEVI, 2013, p. 1).

Como tentativa de se prevenir o aparecimento de doenças, trata-se de uma prática ancestral, que remonta à Antiguidade, cujas descrições mais completas advêm do ano 1000 d.C., na região da Índia, com uma técnica conhecida como "variolação”, que consiste "na inoculação de material obtido pela remoção das cascas das pústulas, a seguir moídas e aplicadas por esfregaço na pele ou por inoculação nas narinas” (LEVI, 2013, p. 6), a qual, no decurso do tempo, mostrou-se arriscada, porém eficaz.

Todavia, o “formato" vacinatório mais moderno e próximo do atual deve sua existência ao inglês Edward Jenner, que, em 1796, depois de duas décadas de estudos, evidenciou a possibilidade de imunização em seres humanos por meio da inoculação de substâncias extraídas da lesão pustular humana de varíola bovina ${ }^{1}$. Na sequência, após ter conseguido, com êxito, vacinar um menino de oito

1 A propósito, o termo “vacina” é derivado da palavra latina “vacca”. 
anos de idade, o pesquisador inglês tentou apresentar suas descobertas na Real Sociedade de Londres, mas seu pedido foi rejeitado (LEVI, 2013, p. 5).

As primeiras ações contra a prática vacinatória, contudo, são ainda mais antigas. Por exemplo, como explica o médico infectologista Guido Levi (2013, p. 20), já em 1722, o teólogo inglês Edmund Mossey pregava que “doenças são enviadas por Deus para punir pecados, e que qualquer tentativa de prevenir a varíola por inoculação é uma operação diabólica”. Posteriormente, mas seguindo a mesma lógica, alguns fiéis quakers, na Inglaterra, e batistas, na Suécia, se posicionavam firmemente contra a vacina da varíola, sob o argumento de que seria um grave pecado usar a vacinação para evitar que alguém morra de varíola, se foi exatamente essa a vontade de Deus (LEVI, 2013, p. 20).

No Brasil, as primeiras tentativas de imunização foram feitas em 1811, ainda durante o Período Joanino, quando da criação da Junta Vacínica da Corte, que passou a utilizar o método criado por Jenner. Já na vigência da República, em 1892 foi criado o Instituto Vacínico Municipal, que desenvolveu uma ampla prática vacinatória na cidade do Rio de Janeiro, a partir de verbas públicas e do conhecimento biomédico da época (MATTOS, 2005).

Foi no período subsequente que ocorreu, no Rio de Janeiro, a Revolta da Vacina - um dos eventos mais marcantes da Primeira República e com motivações muito mais complexas do que o mero fato de a população não querer ser vacinada (na verdade, o motim foi muito mais contra a violência estatal do que contra a vacina em si). Nesse sentido, o historiador Revelino Leonardo Pires de Mattos (2005) entende que “as pessoas que se rebelaram naqueles dez dias da Revolta estavam fazendo-o não só pelo acúmulo de ações autoritárias, ou por estarem perdendo suas moradias; era mais que isto [;] estavam, também, perdendo o controle sobre seus próprios corpos”.

Na seara jurídica, o grande pivô da Revolta da Vacina foi a Lei $n^{0} 1.261 / 1904$, sancionada pelo então presidente Rodrigues Alves, que tornou a vacinação e a revacinação contra a varíola obrigatórias em todo o País. A vacinação deveria ser praticada até o sexto mês de idade da criança, enquanto a revacinação seria feita sete anos depois, sempre repetida por septênios (BRASIL, 1904a).

Seria uma lei bastante simplória, com seus três únicos artigos, se sua aplicação não tivesse se dado de forma tão truculenta e se a alínea $e$ do seu artigo $2^{\circ}$ não invocasse o império do Decreto $n^{\circ}$ 1.151, de 5 de janeiro de 1904. Tal norma, por sua vez, que previa a reorganização dos serviços de higiene do Brasil ante os muitos casos de varíola, previa, por exemplo:

1. A apprehensão e destruição de generos deteriorados ou considerados nocivos á saúde, assim como a cassação de licença fechamento, serão feitos por simples actos da autoridade administrativa; o sequestro e venda de animaes ou objectos cuja existencia nas habitações fôr 
prohibida, depois da competente apprehensão pela autoridade administrativa, serão feitos pela autoridade judicial por meio do processo que fôr estabelecido.

II. A declaração de interdicção de predios, obras e construcções por parte da autoridade administrativa terá por effeito:

Quanto aos predios:

$1^{\circ}$ Serem elles desoccupados amigavel ou judicialmente pelos inquilinos dentro de um a oito dias, conforme a urgencia;

$2^{\circ}$ Serem reparados ou demolidos pelos seus proprietarios no prazo que lhes fôr assignado. Si estes se recusarem fazel-o, as reparações ou demolições serão feitas á sua custa, ficando em um ou outro caso o predio ou terreno por elle occupado legalmente hypothecado para garantia da despeza feita, classe o dia da declaração da interdicção.

Quanto ás obras e construcções:

$1^{\circ}$ Serem ellas immediatamente suspensas;

$2^{\circ}$ Serem reparadas ou demolidas nas mesmas condições e com os mesmos onus que os prédios (BRASIL, 1904b).

Pelo excerto, pode-se notar a dureza das medidas a serem tomadas em nome da saúde pública. Porém, mais do que isso, chama a atenção a prontidão da administração pública, à época, para efetivar tais normas, por meio, inclusive, da complementação e fortalecimento das regras já editadas. Por exemplo, dois meses depois, foi editado o Decreto $n^{\circ} 5.156$, de 8 de março de 1904, que, na mesma linha, deu novo regulamento aos serviços sanitários a cargo da União e, entre outras previsões, em seu artigo 22, XIII, atribuiu competência aos delegados de saúde para ordenar o fechamento (provisório ou definitivo) das casas infectadas ou em precárias condições de higiene. De tais residências deveriam ser retirados seus moradores "quando nenhum inconveniente mais puder ressaltar para a saúde pública” (BRASIL, 1904c).

Acredita-se que os dizeres finais desse dispositivo legal se referiam ao "serviço de profilaxia geral das moléstias infectuosas”, que abrangia a notificação, a desinfecção, a vigilância médica e o isolamento. Todas as quatro possibilidades eram medidas duras tomadas contra o doente, sua família ou seu domicílio, em nome da saúde pública. Por exemplo, no caso da desinfecção, se houvesse resistência por parte do proprietário, previa-se a pena de multa ou de prisão de 8 dias a um mês e, nos casos mais graves, em que a residência estivesse em más condições de higiene ou oferecesse excessiva aglomerações de moradores, o prédio deveria ser desocupado para sofrer “os convenientes expurgos” (BRASIL, 1904c). Constata-se, desse modo, a flagrante restrição ao direito fundamental à inviolabilidade de domicílio, prevista na então vigente Constituição de 1891 (BRASIL, 1891), além da violência policial, prisões arbitrárias e, inclusive, desterro para o Acre, expedientes que serviam duplamente - às metas higienistas, bem como às políticas de exclusão social (JIMENEZ CANTISANO, 2015, p. 300).

Para Pedro Jimenez Cantisano, a insatisfação da população carioca da época remontava às políticas sanitaristas iniciadas no período imperial, durante as décadas de 1870 e 1880, que justificaram campanhas higienistas. Segundo o autor: 
Desenvolveu-se, então, entre a população do Rio de Janeiro, um sentimento "vacinophobico", baseado tanto em conhecimento científico médico-sanitário quanto em uma variedade de tradições culturais afrobrasileiras, contrárias à interferência médica indevida. Esta longa história de rejeição à vacina na cidade ajuda a explicar os acontecimentos de novembro de 1904. A autorização dada aos agentes do Estado para entrar nas residências cariocas e vacinar forçadamente a população desencadeou atos de violência (JIMENEZ CANTISANO, 2015, p. 299, grifo nosso).

Tal afã sanitarista deu-se, como se pode perceber, de forma catastrófica e complexa, de modo a demonstrar que a Revolta de 1904 foi o ápice de uma série de outros eventos e fatores que desagradaram a população carioca da época. Assim, defende-se que os textos apresentados evidenciam dois pontos importantes: i) a Revolta da Vacina não foi um movimento de pessoas desinformadas que ignoravam os benefícios da imunização, mas um conjunto de atos promovidos por uma população descontente contra a violência de um governo que afetava sobretudo os vulneráveis (afinal, quem, se não os mais pobres, viviam em prédios com "excessiva aglomeração de moradores”?); ii) o direito à saúde, da forma como era entendido em 1904 ou como é interpretado atualmente, se serve para justificar intervenções tão flagrantes na vida dos indivíduos (em seus corpos, em suas propriedades, etc.), obrigatoriamente tem que comportar uma dimensão negativa que, em vez de exigir prestações fáticas do Estado, ao contrário, afasta ações indesejadas - ideia que será mais bem discutida nos itens seguintes.

Ainda quanto às considerações históricas, tem-se que, na década de 1920, houve a criação do Departamento Nacional de Saúde Pública, além da ampliação das atribuições do Instituto Oswaldo Cruz (antigo Instituto Soroterápico Federal), que passou, por exemplo, a ter a responsabilidade pela produção da vacina antivariólica. Já em 1941, durante a Era Vargas, no contexto da reestruturação ministerial da época criaram-se “doze serviços nacionais direcionados a doenças específicas, em que se incluíam o controle de lepra, tuberculose, febre amarela, malária, peste e doenças mentais, além de outros serviços, dos quais cinco estavam relacionados a atividades de saúde diversas” (FERNANDES; CHAGAS; SOUZA, 2011, p. 482).

Entretanto, foi só em 1975 que o Brasil voltou a ter legislação específica sobre o tema da vacinação. Nesse ano, foi editada a Lei 6.259, a qual, ainda vigente, regulamenta o Programa Nacional de Imunizações, de competência do Ministério da Saúde (BRASIL, 1975). É interessante destacar que essa lei adota como medidas de saúde pública referentes à imunização a vigilância epidemiológica e a notificação compulsória de doenças, ou seja, reformula os expedientes previstos nas normas de 1904, bem como, felizmente, elimina as hipóteses de desinfecção e de isolamento do programa governamental de saúde pública. 
A Lei 6.259/1975 é regulamentada pelo Decreto 78.231/1976, o qual, em seu artigo 27 e seguintes, torna obrigatórias as vacinações tal como definidas pelo Ministério da Saúde contra as doenças imunopreveníveis e estabelece o dever, de todo cidadão, de submeter a si e aos menores dos quais tenha a guarda ou responsabilidade à vacinação obrigatória (BRASIL, 1976). Ademais, o próprio decreto, no parágrafo único do artigo 29, prevê a dispensa do dever de vacinação obrigatória na hipótese de o indivíduo apresentar atestado médico de contraindicação da aplicação da vacina (BRASIL, 1976).

Por fim, o Estatuto da Criança e do Adolescente (BRASIL, 1990), em seu artigo 14, parágrafo primeiro, reafirma a vacinação obrigatória de todas as crianças nos casos recomendados pelas autoridades sanitárias.

\section{CONSIDERAÇÕES SOBRE OS MOVIMENTOS ANTIVACINA E SUAS JUSTIFICATIVAS}

Levi (2013, p. 11) identificou quatro principais crenças que motivam os grupos antivacina, quais sejam: as religiosas, as filosóficas, o medo de eventos adversos (efeitos colaterais e desenvolvimento de doenças) e a orientação médico-profissional. Nessa última categoria, em que o próprio médico orienta o paciente a não ser imunizado, tal posicionamento pode ser radical (contra qualquer espécie de vacina) ou seletivo (contra algumas imunizações em algumas hipóteses). Além disso, a não vacinação pode se dar por mero descuido, displicência ou ignorância, tanto por parte do médico quanto do indivíduo ou de seus familiares (LEVI, 2013, p. 12).

Contudo, a maioria dessas crenças parece confluir para as mesmas teorias formuladas a partir de pesquisas científicas que vinculam a imunização a graves prejuízos para a saúde e qualidade de vida do indivíduo. É que, no ano de 1998, o médico inglês Andrew Wakefield apresentou um estudo em que inter-relacionava autismo e vacinação. Na pesquisa, ele analisou o organismo de 12 crianças com comportamentos autistas e inflamação intestinal grave que também tinham em comum vestígios do vírus de sarampo no corpo. Por isso, em suma, ele e seus colegas levantaram a hipótese de existir um vínculo causal desses “problemas” com a vacina MMR, que imuniza contra o sarampo, a rubéola e a caxumba e que fora aplicada em 11 das 12 crianças estudadas (IDOETA, 2017).

Entretanto, imediatamente após a publicação, a pesquisa sofreu severas críticas quanto à sua metodologia, pelo fato de o estudo ser não controlado, de casuística pequena (apenas 12 crianças), além da inconsistência nos resultados. Alguns anos depois, descobriu-se que Wakefield recebera dinheiro de alguns advogados que trabalhavam em casos de indenização por danos vacinais. “ $O$ 
julgamento contra Wakefield e alguns colaboradores foi instalado pelo General Medical Council (GMC) do Reino Unido em 2004. Em 24 de maio de 2010, foi emitido o veredicto de culpabilidade por conduta profissional errônea grave, tendo Wakefield seu registro profissional cassado” (LEVI, 2013, p. 41).

Todavia, as pesquisas de Wakefield geraram efeitos que ainda hoje repercutem no mundo todo. Por exemplo, o site GreenMedinfo ${ }^{\circledR}$, “a ciência da cura natural”, publicou, em fevereiro de 2017, artigo intitulado CDC, WHO and Big Pharma Collaborate to Conceal Vaccine-Autism Link Data from Public, de autoria dos estadunidenses Richard Gale e de Gary Null, este último um conhecido crítico da medicina convencional. Segundo os autores, em um texto que apresenta 20 referências bibliográficas,

O público precisa exigir um debate nacional entre aqueles que defendem a vacinação obrigatória e aqueles que os desafiam. Mais do que nunca, é imperativo ter esse diálogo, pois os interesses privados controlados infiltram-se nas salas dos legisladores para fazer lobby. É altamente previsível que as taxas de autismo aumentarão à medida que mais vacinas chegarem ao mercado e os estados exigirem seguir o calendário de vacinação do CDC. O público precisa ser educado sobre a ciência e então decidir por si mesmo. (GALE; NULL, 2017, tradução nossa) ${ }^{2}$

Em tom altamente combativo, os autores sintetizam grande parte dos argumentos utilizados contra a vacinação obrigatória, que se pautam sobretudo na desconfiança. Por outro lado, apesar do viés conspiratório, tanto esse artigo quanto os argumentos de várias outras frentes antivacina apresentam considerações interessantes acerca, por exemplo, da forma unilateral e desprovida de diálogo e de participação popular com que a imunização tem sido imposta à sociedade.

Nesse sentido, para Sueli Gandolfi Dallari (2018, p. 11), a obrigação da vacina não se furta das exigências da "ampla participação popular (leiga e especializada), tanto no momento de fixação da norma que exprime o direito - e seu alcance - quanto na sua realização no caso concreto”, o que consistiria na única forma de se alcançar o equilíbrio entre liberdade e controle na questão da obrigação vacinal. É que, como ficou mais que evidenciado nos fatos ocorridos durante a Revolta de 1904, a imunização não deixa de ser uma forma brusca de interferência num dos bens mais íntimos do indivíduo: seu próprio corpo.

Outra pesquisa interessante sobre o tema é a que foi realizada por Barbieri, Couto e Aith (2017) no período de janeiro a julho de 2017 com 15 casais de classe média da cidade de São Paulo,

2 No original: "The public needs to demand a national debate between those who advocate for mandatory vaccination and those who challenge them. More than ever before it is imperative to have this dialogue as privately controlled interests infiltrate the halls of state legislators to lobby for state-wide mandates. It is highly predictable that autism rates will escalate as more vaccines come to market and states mandate the CDC's vaccination schedule. The public needs to be educated about the science and ultimately decide for themselves.” 
dos quais todos tinham nível superior e alguns também tinham especializações, mestrado e doutorado, e dos quais apenas um participante estava desempregado. Os pesquisadores dividiram os participantes em três grupos iguais, nos quais o primeiro vacinava os filhos, o segundo selecionava as vacinas e o terceiro não vacinava.

No primeiro grupo, dos casais que vacinavam os filhos, "a tomada de decisão foi quase automatizada, influenciada pela reprodução de uma tradição familiar e pela credibilidade da conduta pediátrica, com consequente ratificação da vacinação infantil como uma prática social valorada e legitimada” (BARBIERI; COUTO; AITH, 2017, p. e00173315). No segundo, “os casais seletivos se auto atribuíram a prerrogativa da autonomia dos cuidados dos filhos mesmo diante de normatizações generalizadas”, em que a particularização do que seria melhor para os filhos se sobrepunha à norma genérica bem como ao calendário de vacinação do Ministério da Saúde (BARBIERI; COUTO; AITH, 2017, p. e00173315).

No terceiro grupo, por sua vez, os pais não atribuíam à vacinação um valor positivo e questionavam a prática como favorável à saúde das crianças; para eles, tanto o Programa Nacional de Imunização quanto as vacinas de modo geral mostravam-se totalmente ilegítimas. Ademais, os autores destacam que os argumentos mais utilizados pelos pais que optaram por não vacinar seus filhos se referiam à alegação de que a doença é demasiado leve ou já estaria eliminada, ao receio quanto aos eventos adversos, à crítica em relação às substâncias que compõem às vacinas, à sua eficácia, ao calendário oficial de vacinação e aos interesses financeiros da indústria farmacêutica, além de, nos casos daqueles que prezam uma vida “natural”, à escolha por outras forma de proteção à saúde (BARBIERI; COUTO; AITH, 2017, p. e00173315).

Desse estudo, constata-se que a recusa à vacinação pode se dar por diversos motivos e diversas formas. Chama-se a atenção sobre a vacinação seletiva, por exemplo, que não é uma oposição absoluta a todas as vacinas, mas uma crítica ao modo como elas são fixadas e impostas, de forma genérica, à toda a população. É, pois, uma resistência parcial à imunização. Quanto àqueles que são totalmente contrários à imposição vacinal, ainda que deles de discorde e se aponte a prevalência da saúde pública em detrimento das escolhas individuais, há que se levar em conta a razoabilidade dos seus argumentos, no que se refere à composição, ao calendário oficial muito restrito e aos inegáveis lucros auferidos pela indústria farmacêutica. 


\section{O DIREITO FUNDAMENTAL À SAÚDE E O DEVER FUNDAMENTAL DA VACINAÇÃO}

Parte significativa da doutrina dos direitos fundamentais costuma sustentar que os "direitos civis” seriam direitos de não intervenção, pelo que o Estado não poderia intervir na liberdade do indivíduo, enquanto os “direitos sociais” seriam direitos de prestação, por meio dos quais o Estado deveria prover bens e serviços à população ${ }^{3}$. Nesse sentido, por exemplo, Dimitri Dimoulis e Leonardo Martins (2011, p. 51) entendem que os direitos de resistência são os mesmos que aparecem nas declarações dos século XVIII e “correspondem à concepção liberal clássica que procura impor limitações à atividade do Estado, para preservar a liberdade pessoal”, enquanto os direitos sociais correspondem àqueles "garantidos a partir das primeiras décadas do século XX na Rússia pósrevolucionária, na Alemanha da República de Weimar e em outros países com forte presença do movimento socialista” (DIMOULIS; MARTINS, 2011, p. 52), que corresponderiam, respectivamente, aos direitos chamados de primeira geração ou dimensão e de segunda geração ou dimensão.

Entretanto, tais teorias, atualmente, não se sustentam. Por exemplo, tem-se que, para se garantir as liberdades e o exercício dos direitos políticos, o Estado deve estruturar o Poder Judiciário, com todos os seus órgãos, servidores, equipamentos, sistemas, etc., ou seja, prover bens públicos relacionados à fruição dos direitos “civis”, ou direitos de liberdade, da mesma forma que se deve prover bens públicos em relação aos direitos sociais. Igualmente, também os direitos sociais, em específico o direito à saúde, comporta uma dimensão negativa, que exige a não interferência estatal. Como explica Jorge Reis Novais (2010, p. 128):

Os tradicionais direitos de liberdade também seriam direitos sociais em sentido lato, no
sentido de que, por força da sua inserção comunitária, também eles careceriam de uma
conformação em grande medida baseada em prestações; de facto, a generalidade dos
tradicionais direitos civis e políticos exige igualmente, tal como os direitos sociais, a
realização de actuações e prestações estatais positivas, sem as quais ou não podem exercer-
se ou não podem ser efectivamente garantidos (por exemplo, não é possível exercer-se o
direito de voto sem a organização jurídica, material, institucional, de todo o processo
eleitoral). Da mesma forma, e ao invés, também os direitos sociais seriam de algum modo
direitos negativos, uma vez que também deles é possível deduzir obrigações estatais de
omissão. Por exemplo, o direito à protecção da saúde envolve necessariamente, da parte do
Estado, a obrigação de não atentar contra a saúde dos particulares ou contra o acesso aos
cuidados de saúde garantidos aos particulares ou assegurados por eles próprios, com os seus
recursos.

Também Ingo Sarlet (2007, p. 8), ao analisar o direito à saúde, entende que ele pode ser considerado como norma jusfundamental que constitui, além do clássico direito prestacional que

3 Sobre esse entendimento, cf. BOBBIO, 2004. 
impõe ao Estado a realização de políticas públicas, um direito de defesa, que afasta intervenções estatais indevidas na integridade psicofísica do indivíduo. Considera-se, desse modo, que o direito à saúde significa que o sujeito tem a faculdade de resistir a ingerências em seu corpo, inclusive no sentido de decidir sobre como preservar e recuperar sua saúde. Essa possibilidade de decisão significa ser informado acerca da sua situação de saúde e das recomendações para seu tratamento, e, diante delas, poder escolher livre e conscientemente ${ }^{4}$. Nesse mesmo sentido, o Código de Ética Médica ${ }^{5}$, em seu art. 31, IV, estabelece que é vedado ao médico "desrespeitar o direito do paciente ou de seu representante legal de decidir livremente sobre a execução de práticas diagnósticas ou terapêuticas, salvo em caso de iminente risco de morte.”6

Os deveres fundamentais, por sua vez, são também de extremo relevo, pois imprescindíveis para a garantia dos direitos fundamentais. A ideia de dever fundamental, via de regra, advém da concepção prévia de determinado direito fundamental, como comportamento obrigatório por parte do Estado - ou de particulares, em casos específicos e expressos - para que o direito ao qual se vincula possa ser realizado, ainda que potencialmente. Alguns encontram-se expressos na própria Constituição (por exemplo, dever de alistamento obrigatório), outros são decorrentes do texto constitucional, ainda que implícitos. Nessa esteira, Dimoulis e Martins (2011, p. 59) apontam a existência de diversas categorias, entre as quais se destacam: i) deveres estatais implícitos não autônomos: metaforicamente, são o reflexo do direito fundamental no espelho, ou seja, são os deveres que correspondem a um direito fundamental. Por exemplo, se um indivíduo tem o direito à educação assim garantido na Constituição, o Estado tem o dever de lhe prover tal direito; ii) deveres estatais explícitos não autônomos: previstos expressamente pela norma constitucional. Por exemplo, quando o art. 5, LXXV, estabelece que o Estado deverá indenizar o condenado por erro judicial; iii) deveres autônomos dos particulares: atribuídos pela Constituição a determinadas categorias da população, por exemplo, a educação, dever do Estado e da família (DIMOULIS; MARTINS, 2011, p. 59).

No que tange aos deveres fundamentais relacionados ao direito à saúde, Sarlet e Figueiredo (2008) ressaltam dois pontos pertinentes para este estudo. O primeiro é que eles podem impor

4 A melhor forma de manifestação da vontade do paciente é por meio de um termo de consentimento, que consiste num “documento em que o paciente, após ter recebido todas as informações e sanado todas as dúvidas sobre um ou mais procedimentos terapêuticos e diagnósticos, manifesta seu consentimento ao médico para que sejam realizados.” (MABTUM; MARCHETTO, 2015, p. 79).

5 Disponível em: https://bit.ly/2Eouae1. Acesso em: 4 out. 2019.

6 Ugarte e Acioly (2014, p. 275) apontam como prática recomendável quanto à harmonização entre a vontade do paciente e a do médico o modelo participativo, que estaria situado entre os extremos da autonomia total do paciente e do paternalismo médico. Segundo os autores, "o modelo participativo pode ser considerado como o ideal do ponto de vista ético, no qual o médico informa, orienta e aconselha o paciente, através do encorajamento, à tomada de decisões livre e consciente”. 
obrigações de caráter originário, como, por exemplo, as políticas públicas de implementação do Sistema Único de Saúde (SUS) e o dever geral de respeito à saúde dos indivíduos (não causar danos à saúde de ninguém); mas também podem impor obrigações derivadas, como o respeito à ampla gama de normas que regulam a matéria sanitária, inclusive aos suprarreferidos Lei 6.259/1975 e Decreto 78.231/1976, marcos regulatórios da vacinação obrigatória no Brasil. O segundo ponto diz respeito à titularidade desses deveres, uma vez que, embora o Estado seja o titular da maior parte deles, tal fato “não afasta uma eficácia no âmbito privado, sobretudo em termos de obrigações derivadas” (SARLET; FIGUEIREDO, 2008, p. 7). Para os autores, inclusive, “a noção de deveres fundamentais conecta-se ao princípio da solidariedade, no sentido de que toda a sociedade é também responsável pela efetivação e proteção do direito à saúde de todos e de cada um” (SARLET; FIGUEIREDO, 2008, p. 7) - explicação adequada para o contexto da imunização.

Nessa linha, pode-se afirmar que, a partir da classificação de Dimoulis e Martins (2011), a saúde revela-se como um dever explícito não autônomo, de acordo com o que foi expresso nos artigos 196 e 198 - este, que ordena a estruturação do Sistema Único de Saúde - da Constituição Federal. Para Sarlet e Figueiredo (2008), da mesma forma, a saúde também se trata de um dever, mas classificado como autônomo e dirigido aos particulares - por exemplo, o dever de respeito às normas da Agência Nacional de Vigilância Sanitária e, como já dito, às regras de vacinação impostas pelo Ministério da Saúde.

Percebe-se, assim, que a teoria dos deveres fundamentais é muito mais complexa, não sendo apropriado explicá-los como a correspondência de um direito. Esses deveres, por sua natureza, impõem limitações e restrições ao exercício dos direitos, sobretudo das liberdades. É a clássica afirmação de que, para o exercício do direito de um indivíduo deve haver a limitação do direito do outro ${ }^{7}$.

Por conseguinte, em relação (ao direito) à saúde, entende-se que as duas dimensões que o integram (positiva/prestacional e negativa/defensiva) estão em constante tensão, porque a dimensão positiva exige o cumprimento de deveres fundamentais, de titularidade do Estado - por exemplo, o dever fundamental estatal do fornecimento de medicamentos essenciais -, mas também de titularidade dos indivíduos. Entre esses deveres de titularidade dos particulares, encontra-se o dever de vacinação (um dever decorrente, de titularidade dos particulares), o qual não deixa de ser, também, uma limitação à dimensão negativa do direito à saúde. Sem essa dimensão, todavia, a dimensão positiva

\footnotetext{
Ideia mais bem desenvolvida nos parágrafos seguintes.
} 
do mesmo dever não pode ser efetivada, motivo pelo qual essas duas dimensões estão em natural e constante tensão, que não pode ser afastada.

A vacinação revela-se, pois, como dever constitucional decorrente do direito fundamental à saúde, dirigido ao Estado. Por exemplo, ainda que haja um indivíduo que se esquive da vacinação, ele próprio, bem como todos os outros, são titulares do direito à saúde, que o Estado deve respeitar, proteger e promover (NOVAIS, 2010). As pessoas têm direito a uma situação de saúde pública adequada, e, por esse direito, cada sujeito tem o dever de ser imunizado - ainda que isso constitua uma limitação à dimensão negativa do direito à saúde.

Não se pode ignorar, entretanto, que, ao se limitar uma dimensão de um direito, limita-se o próprio direito. Porém, caso essa limitação seja necessária para garantir a outra dimensão desse mesmo direito, ela seria uma espécie de limitação inevitável. Portanto, tem-se que não se trata de uma limitação inadequada, mas, como já dito, necessária, sem a qual o direito à saúde não é passível de efetivação.

A propósito dos limites e restrições dos direitos fundamentais, mostra-se pertinente a teoria desenvolvida por Virgílio Afonso da Silva (2006, p. 47), para quem, a priori, “todos os direitos fundamentais são restringíveis e todos os direitos fundamentais são regulamentáveis”. Por essa via, o autor refuta a ideia de que as normas jusfundamentais seriam dotadas de limites imanentes, como também nega a hipótese de que o suporte fático desses direitos é restrito - ambas, teorias que teriam como consequência a proteção apenas parcial de um direito fundamental. Silva, contudo, ao responder ao questionamento sobre o que é protegido pelos direitos fundamentais, afirma que:

[...] toda ação, estado ou posição jurídica que possua alguma característica que, isoladamente considerada, faça parte do "âmbito temático" de um determinado direito fundamental, deve ser considerada como abrangida por seu âmbito de proteção, independentemente da consideração de outras variáveis. A definição é propositalmente aberta, já que é justamente essa abertura que caracteriza a amplitude da proteção (SILVA, 2006, p. 34).

Isso não significaria, por óbvio, que os direitos fundamentais são absolutos, pois não são. Todos eles podem sofrer uma intervenção estatal, ação que não corresponde a uma violação. Isso porque a intervenção estatal deve ser sempre acompanhada de uma fundamentação constitucional para que se configure como uma restrição permitida e, portanto, constitucional (SILVA, 2006, p. 35). Daí porque se entende que a imposição da vacinação obrigatória, enquanto restrição ao direito à saúde, seria justificada como proteção ao próprio direito à saúde - agora em caráter público.

Também para Dimoulis e Martins (2011, p. 137), os limites aos direitos fundamentais são espécie de intervenção, que se define como a ação ou omissão estatal que "impossibilita um comportamento correspondente a um direito fundamental abrangido pela área de proteção do referido 
direito" e que "liga ao seu exercício uma consequência jurídica negativa (proibição acompanhada de sanção”. Dessa feita, a intervenção (constitucionalmente justificada) é permitida, entre outros casos, na hipótese de o ato interventivo representar "a concretização de um limite constitucional derivado do chamado direito constitucional de colisão”, realizada, num primeiro plano, pelo legislador (DIMOULIS; MARTINS, 2011, p. 143).

Para os mesmos autores, a concretização de qualquer direito fundamental por meio da legislação infraconstitucional pode significar alguma forma de limitação (DIMOULIS E MARTINS, 2011, p. 145). Aqui, deve-se destacar que as normas que regulam o Programa Nacional de Imunizações e as ações de vigilância epidemiológica, ainda que anteriores à Constituição de 1988, foram por ela recepcionadas e se trata, na prática, de concretização do direito à saúde, que, embora o limitem, institucionalizam políticas públicas que permitem sua efetivação, razão pela qual tal limitação, de forma genérica, considera-se justificada ${ }^{8}$.

É também como entende Sueli Gandolfi Dallari (2018, p. 10, grifo nosso):

[...] é preciso compreender o que é protegido pelas referidas leis [que instituem a vacinação obrigatória]. E a resposta é complexa, pois, ao mesmo tempo em que se almeja proteger a saúde de cada pessoa que receberá a vacina, visa-se a proteger a coletividade com a expressiva diminuição dos agentes causadores das moléstias evitáveis pela vacina. Tem-se, então, caracterizada a proteção ao direito fundamental à saúde, não só individual como também coletiva. Quanto às possíveis restrições postas à implementação do direito à saúde, podem-se enumerar o direito à liberdade individual, que assegura a escolha de não se submeter aos riscos de efeitos adversos da vacina ou o direito à educação, ou ainda, o direito à liberdade profissional. Isso sem esquecer a inclusão do processo de produção e comercialização de medicamentos e vacinas no sistema capitalista, que implica a auferição de lucro. No caso brasileiro, todos esses direitos fundamentais encontram abrigo expresso no texto constitucional. E não se diga que o Estado não está obrigado a intervir, regulando ou regulamentando as situações concretas para a realização de cada um dos direitos declarados. Bem ao contrário, ele está amplamente obrigado à proteção de cada um desses direitos fundamentais. Espera-se, portanto, que o sistema judicial fundamente, argumentando amplamente a partir da consideração da situação concreta, a opção pela proteção adotada.

Defende-se, assim, que a intervenção no direito à saúde deva respeitar a proporcionalidade, desdobrada em necessidade, adequação e proporcionalidade em sentido estrito (DIMOULIS; MARTINS, 2011, p. 173). In casu, a intervenção deve: ser necessária para a saúde coletiva e/ou individual; ser feita de forma adequada, com a escolha dos meios menos gravosos, que afetem o mínimo possível as escolhas do indivíduo no âmbito do seu corpo e da sua saúde; e, por fim, proceder à ponderação sobre se os benefícios obtidos justificariam tal intervenção.

8 Entretanto, ainda que as normas sobre imunização tenham sido recepcionadas pela Constituição de 1988, não podem, jamais, sobrepor-se às normas constitucionais, inclusive aos princípios que protegem a dignidade da pessoa humana e as liberdades individuais. 
Mais concretamente, sobre a intervenção no direito à saúde feita com a obrigação de se vacinar, além dos critérios apontados por Dallari (2018) (ampla participação popular, leiga e especializada, na fixação da legislação epidemiológica), exige-se que a participação popular também se dê no processo de aquisição de vacinas, que devem ser sempre de boa qualidade, devidamente testadas e certificadas pelos órgãos competentes para tanto, seguras e que gerem o mínimo de eventos adversos para seu público-alvo.

\section{CONSIDERAÇÕES FINAIS}

A vacinação é uma prática que tem sido utilizada no Brasil e no mundo há mais de dois séculos como política pública de saúde coletiva, com fins de conter o aparecimento e o alastramento de doenças infectocontagiosas. Sua eficácia tem sido demonstrada de diversos modos durante todo esse período, o que não impediu, contudo, que grupos variados se oponham às políticas de imunização.

Assim, por um lado, têm-se, no Brasil, três normas principais que regulam a vacinação obrigatória: a Lei 6.259/1975 (que institui o Programa Nacional de Imunizações), o Decreto 78.231/1976 (que regulamenta o dispositivo anterior) e a Lei 8.069/1990 (Estatuto da Criança e do Adolescente, que, de forma mais específica, ratifica a obrigatoriedade da vacinação de crianças e adolescentes nas hipóteses recomendadas pelas autoridades sanitárias). Por outro lado, há notícias, pelo menos desde o século XVIII, de grupos que se manifestam contrariamente à vacinação, com destaque para a Revolta da Vacina, no Brasil, já no século XX. Ademais, atualmente, tem-se que esses grupos se motivam sobretudo por causas religiosas, filosóficas, medo de eventos adversos ou por orientação médico-profissional. A resistência à vacina pode ser total ou parcial e, como apresentado, há indivíduos com diversos níveis de escolaridade que se opõem à imunização obrigatória, não se podendo admitir, portanto, o argumento de que são pessoas meramente desinformadas ou ignorantes.

Com tudo o que foi narrado, torna-se clara a percepção de que o tema vacinação está em constante tensão, com suas múltiplas dimensões que abarcam classificações diversas e concomitantes quanto à sua representação, tendo em vista o direito à saúde: a vacinação é espécie de direito individual (daquele que almeja - ou não - ser vacinado) e coletivo (já que os efeitos da vacinação estão relacionados à coletividade toda se submeter ao procedimento, sob pena de a não vacinação individual colocar em xeque a imunização coletiva), tendo ainda uma feição negativa (já que exige 
abstenção do Estado de intervir desarrazoadamente na saúde das pessoas) e outra positiva (na medida em que determina a obrigação de o Estado garantir/concretizar o direito à saúde).

Ainda assim, ante todo esse debate, não é fácil alcançar uma resposta definitiva para a natureza jurídica da vacinação, se direito ou dever jurídico, sendo necessário, então, construir o trajeto argumentativamente. Em todo o artigo defendeu-se a sobreposição, em situações normais, da vacinação à resistência do particular, tomando-se como ponto de referência a colisão entre o direito fundamental de vacinar (ou não vacinar) e, ainda, sua dimensão positiva e negativa. Notou-se a impossibilidade de tese absoluta ou de uma classificação uníssona quanto à vacinação, que em sua concretização marca-se por uma escolha, de maneira que saber ao certo sua classificação exige ponderação e respeito aos três critérios estabelecidos classicamente pela doutrina: necessidade, adequação e proporcionalidade em sentido estrito.

Desse modo, a conclusão a que se chega é a de que a vacinação como um dos requisitos do direito fundamental à saúde é direito, mas também se trata de um dever fundamental. E que, justamente por ser um dever fundamental, submete-se à dimensão negativa do direito à saúde, uma vez que prevê uma interferência estatal na saúde do indivíduo, independentemente de suas escolhas, crenças, convicções, etc. Todavia, essa relação entre direito/dever fundamental, no caso da vacinação, dá-se de forma muito peculiar, porque, ao se considerar o alto e comprovado nível de eficácia da imunização coletiva, tem-se que tal prática tornou-se uma exigência para a devida efetivação do direito fundamental à saúde. Desse modo, para que a saúde - direito de todos e dever do Estado seja efetivada em âmbito coletivo, deve-se impor a vacinação. Portanto, por meio de um dever (de se vacinar), limita-se a dimensão negativa do direito à saúde de um, para se garantir o direito à saúde em sua totalidade, a todos. Não se olvida que, embora se trate de um dever fundamental e de uma limitação cabível ao direito à saúde, a imposição vacinal não deve fugir às regras e princípios democráticos, inclusive comportando exceções para os casos de indicações médicas, como narrado no corpo do texto e previsto em legislação própria.

\section{REFERÊNCIAS}

BALLALAI, Isabella; BRAVO, Flavia (org.). Imunização: tudo o que você sempre quis saber. Rio de Janeiro: RMCOM, 2016.

BARBIERI, Carolina Luisa Alves; COUTO, Márcia Thereza; AITH, Fernando Mussa Abujamra. A (não) vacinação infantil entre a cultura e a lei: os significados atribuídos por casais de camadas médias de São Paulo, Brasil. Cadernos de Saúde Pública, [s. l.], v. 33, p. e00173315, 2017. 
BOBBIO, Norberto. A Era dos Direitos. Tradução Carlos Nelson Coutinho. Rio de Janeiro: Elsevier, 2004.

BRASIL. Constituição de 1891. Constituição da República dos Estados Unidos do Brasil. Rio de Janeiro, 1891. Disponível em: https://bit.ly/2Fwk37T. Acesso em: 21 dez. 2018.

BRASIL. Constituição de 1988. Constituição da República Federativa do Brasil de 1988. Disponível em: https://bit.ly/3azO2qL. Acesso em: 25 jul. 2018.

BRASIL. Decreto $\mathbf{n}^{\mathbf{0}}$ 1.151, de 5 de janeiro de 1904b. Reorganiza os serviços da hygiene administrativa da União. Disponível em: https://bit.ly/3iIVRgD. Acesso em: 15 dez. 2018.

BRASIL. Decreto no 5.156, de 8 de março de 1904c. Dá novo regulamento aos serviços sanitarios a cargo da União. Disponível em: https://bit.ly/2Y6PJqF. Acesso em: 15 dez. 2018.

BRASIL. Decreto $\mathbf{n}^{0}$ 78.231, de 12 de agosto de 1976. Regulamenta a Lei no 6.259, de 30 de outubro de 1975, que dispõe sobre a organização das ações de vigilância epidemiológica, sobre o programa nacional de imunizações, estabelece normas relativas à notificação compulsória de doenças, e dá outras providências. Disponível em: https://bit.ly/343nE7B. Acesso em: 18 dez. 2018.

BRASIL. Lei $\mathbf{n}^{0}$ 1.261, de 31 de outubro de 1904a. Torna obrigatorias, em toda a Republica, a vaccinação e a revaccinação contra a variola. Disponível em: https://bit.ly/2Y4XEF8. Acesso em: 15 dez. 2018.

BRASIL. Lei $\mathbf{n}^{\mathbf{0}}$ 6.259, de 30 de outubro de 1975. Dispõe sobre a organização das ações de Vigilância Epidemiológica, sobre o Programa Nacional de Imunizações, estabelece normas relativas à notificação compulsória de doenças, e dá outras providências. Disponível em: https://bit.ly/2Y41GgO. Acesso em: 18 dez. 2018.

BRASIL. Lei no 8.069, de 13 de julho de 1990. Dispõe sobre o Estatuto da Criança e do Adolescente e dá outras providências. Disponível em: https://bit.ly/2E5TMwo. Acesso em: 18 dez. 2018.

CANCIAN, Natália. 1 em cada 4 cidades tem cobertura abaixo da meta em todas vacinas infantis. Folha de S. Paulo, São Paulo, 5 jul. 2018. Disponível em: https://bit.ly/31PPZvi. Acesso em: 15 dez. 2018.

DALLARI, Sueli Gandolfi. O eterno conflito entre liberdade e controle: o caso da vacinação obrigatória. Revista de Direito Sanitário, São Paulo, v. 18, n. 3, p. 7-16, nov. 2017/fev. 2018. Disponível em: https://bit.ly/310K6fm. Acesso em: 13 dez. 2018.

DIMOULIS, Dimitri; MARTINS, Leonardo. Teoria Geral dos Direitos Fundamentais. São Paulo: Atlas, 2011.

FERNANDES, Tania Maria Dias; CHAGAS, Daiana Crús; SOUZA, Érica Mello de. Varíola e vacina no Brasil no século XX: institucionalização da educação sanitária. Ciência \& Saúde

Coletiva, [s. l.], v. 16, n. 2, p. 479-489, 2011. 
GALE, Richard; NULL, Gary. CDC, WHO and Big Pharma Collaborate to Conceal VaccineAutism Link Data from Public. The Good News Today, [s. l.], 13 fev. 2017. Disponível em: https://bit.ly/34d7Krg. Acesso em: 7 out. 2019.

IDOETA, Paula Adamo. A história que deu origem ao mito da ligação entre vacinas e autismo. BBC Brasil, [s. l.], 24 jul. 2017. Disponível em: https://bbc.in/2Ylxv55. Acesso em: 18 dez. 2018.

JIMENEZ CANTISANO, Pedro. Lares, Tribunais e Ruas: a Inviolabilidade de Domicílio e a Revolta da Vacina. Revista Direito e Práxis, Rio de Janeiro, v. 6, n. 11, p. 294-325, 2015. Disponível em: https://bit.ly/30YJxCO. Acesso em: 16 dez. 2018.

LEVI, Guido Carlos. Recusa de vacinas: causas e consequências. São Paulo: Segmento Farma, 2013.

MABTUM, Matheus Massaro; MARCHETTO, Patrícia Borba. Reflexões sobre o consentimento livre e esclarecido. In: $O$ debate bioético e jurídico sobre as diretivas antecipadas de vontade [online]. São Paulo: Editora UNESP; São Paulo: Cultura Acadêmica, 2015, p. 73-87. Disponível em: https://bit.ly/3iEUgs4. Acesso em: 7 out. 2019.

MATTOS, Revelino Leonardo Pires de. Revolta da Vacina (1904): Varíola e Vacinação. In: Laboratório de História Econômica e Social, Juiz de Fora, 13 a 16 de junho de 2005. Anais [...]. Juiz de Fora, 2005. Disponível em: https://bit.ly/31fn7xe. Acesso em: 7 out. 2019.

NOVAIS, Jorge Reis. Direitos Sociais. Teoria jurídica dos Direitos Sociais enquanto Direitos Fundamentais. Coimbra: Coimbra Editora, 2010.

SÃO PAULO (Estado). Ministério Público do Estado de São Paulo (MPSP). MP obtém liminar que obriga pais a vacinar os filhos. 27 set. 2013. Disponível em: https://bit.ly/3kI3kyt. Acesso em: 15 dez. 2018.

SARLET, Ingo Wolfgang. Algumas considerações em torno do conteúdo, eficácia e efetividade do Direito à Saúde na Constituição de 1988. Revista Eletrônica sobre a Reforma do Estado, Salvador, n. 11, p. 1-17, set./out./nov. 2007.

SARLET, Ingo Wolfgang; FIGUEIREDO, Mariana Filchtiner. Algumas considerações sobre o direito fundamental à proteção e promoção da saúde aos 20 anos da Constituição Federal de 1988. Revista de Direito do Consumidor, São Paulo, n. 67, p. 125-172, jul./set. 2008.

SILVA, Virgílio Afonso da. O conteúdo essencial dos direitos fundamentais e a eficácia das normas constitucionais. Revista de Direito do Estado 4, [s. l.], p. 23-51, 2006. Disponível em: https://bit.ly/2PVplLV. Acesso em: 7 out. 2019.

UGARTE, Odile Nogueira; ACIOLY, Marcus André. O princípio da autonomia no Brasil: discutir é preciso... Revista Col. Bras. Cir., [s. l.], v. 41, n. 5, p. 274-277, 2014. Disponível em: https://bit.ly/2DW2TQr. Acesso em: 7 out. 2019. 
José Renato Venâncio Resende Mestrando em Direito

9Lattes iD: http://lattes.cnpq.br/1591205186119384

E-mail: jrenatoresende@gmail.com

Cândice Lisbôa Alves

Doutora em Direito Público

QLattes iD: http://lattes.cnpq.br/0539033278370084

E-mail: candicelisboa.prof@gmail.com 